\title{
A Comparative Study of Pain and Discomfort in Septoplasty with Quilting of Nasal Septum and Nasal Packing
}

\author{
Bista $\mathbf{M}^{*}$ \\ Department of ENT-HN Surgery, Kathmandu Medical College Teaching Hospital, Nepal
}

Submission: February 03, 2018; Published: February 26, 2018

*Corresponding author: Bista M, Department of ENT-HN Surgery, Kathmandu Medical College Teaching Hospital, Kathmandu, Nepal, Tel: 9841256711; Email: meerabista@hotmail.com

\begin{abstract}
Introduction: Rhinologists have to be aware of the excruciating pain exerted by nasal packs on its introduction and removal. Thus the validity of need for nasal packing following septoplasty is considered under study for its most painful symptom.
\end{abstract}

Objective: To compare the degree of pain and discomfort in patients with quilting of nasal septum and nasal packing after septoplasty using visual analogue score (VAS)

Methodology: This is a prospective study done in Kathmandu Medical College in the department of ENT-HN Surgery from January2016 to December 2016.Total of 100 patients undergoing septoplasty for symptomatic deviated nasal septum were included in the study. Severity of degree of pain and discomfort was collected using Visual Analogue Scale (VAS)for the total number of patients with nasal packing and quilting on the day of operation, first post operative day, day of nasal pack removal, day of discharge and first /second follow ups.

Results: Level of pain experienced by patients with quilting on the day of operation, first post operative day, on the day of discharge and first follow up were significantly less than those with packing with $p$ value $<0.001$ in all VAS reading. On the day of pack removal, 29 patients with packing felt most excruciating pain with visual analogue score 10. Eighteen had visual analogue score 9 and only 2 patients felt little pain with visual analogue score of 2. Patients with quilting did not have to bear this level of pain.

Conclusion: Quilting of nasal septum after septal surgeries can be used to avoid pain and discomfort caused by nasal packing. Thus packing of nasal cavity should be avoided where possible and reserved for only those who have bleeding predisposition or complications.

Keywords: Nasal packing; Quilting; Septoplasty; Visual Analogue Score (VAS)

\section{Introduction}

Nasal packing is primarily used to control bleeding in epistaxis as well as endonasal surgery including septoplasty. However it has local effects like severe degree of pain on removal, discomfort due to foreign body sensation and nasal obstruction. Systemic effects may be due to poor sleep quality, respiratory difficulty, decreased oxygen saturation, circulatory problems and toxic shock syndrome [1] which can be severe enough to threaten the life of the patient.

\section{Methodology}

A longitudinal, cross-sectional, prospective study was done in Kathmandu Medical College Teaching Hospital for the duration of one year (January 2016 to December 2016) comprising of hundred patients with symptomatic deviated nasal septum planned for septoplasty was included in the study. Patients under 15 years of age, undergoing septoplasty with other surgeries like functional Endoscopic Sinus Surgery (FESS), rhinoplasty, dacrocystorhinostomy (DCR) and turbinoplasty, patients with revision nasal surgery, those who opted not to get enrolled in the study or follow up were excluded from the study. A Qualitative study where degree of pain and discomfort was collected using Visual Analogue Scale (VAS)for the total number of patients with nasal packing and quilting on the day of operation, first post operative day, day of nasal pack removal, day of discharge and first /second follow ups. Statistical analysis was done using SPSS version 20, student's t test was done and $p$ value $<0.05$ was considered significant.

\section{Results}

There were total 100 patients who underwent septoplasty for symptomatic deviated nasal septum in the study, among them 53 were male and 47 were females. Level of pain experienced 
by the patients with nasal packing and quilting of nasal septum on the day of operation, first post operative day, day of pack removal, day of discharge and first follow up were assessed by using a visual analogue scale (VAS) where $0=$ no pain and $10=$ worst pain ever experienced by the patient. Level of pain experienced by patients with quilting on the day of operation, first post operative day, on the day of discharge and first follow up were significantly less than those with packing (Figures 1-4) with $\mathrm{p}$ value $<0.001$ in all VAS reading (Tables $1 \& 2$ ). On the day of pack removal, 29 patients with packing felt most excruciating pain with VAS $=10,18$ felt VAS $=9$ and only 2 patients felt little pain with VAS $=2$ whereas patients with quilting did not have to bear this level of pain (Figure 5). Thus degree of severity of pain was significantly more in patients with nasal packing than with quilting of nasal septum in patients with septoplasty. Thus in practicing evidence based medicine nasal packing and removal is very painful procedure and has to be practiced only in absolute need.

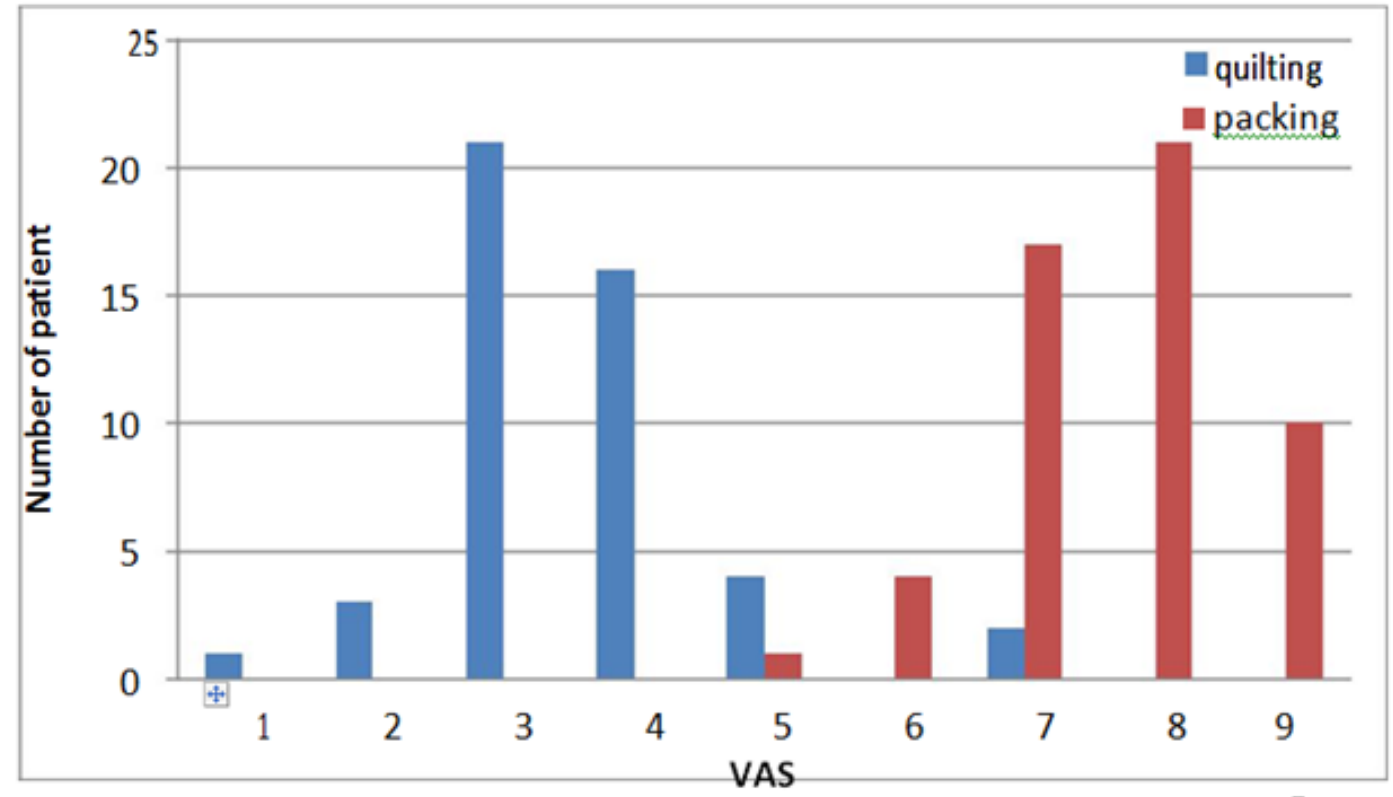

Figure 1: VAS reading on severity of pain on the day of operation.

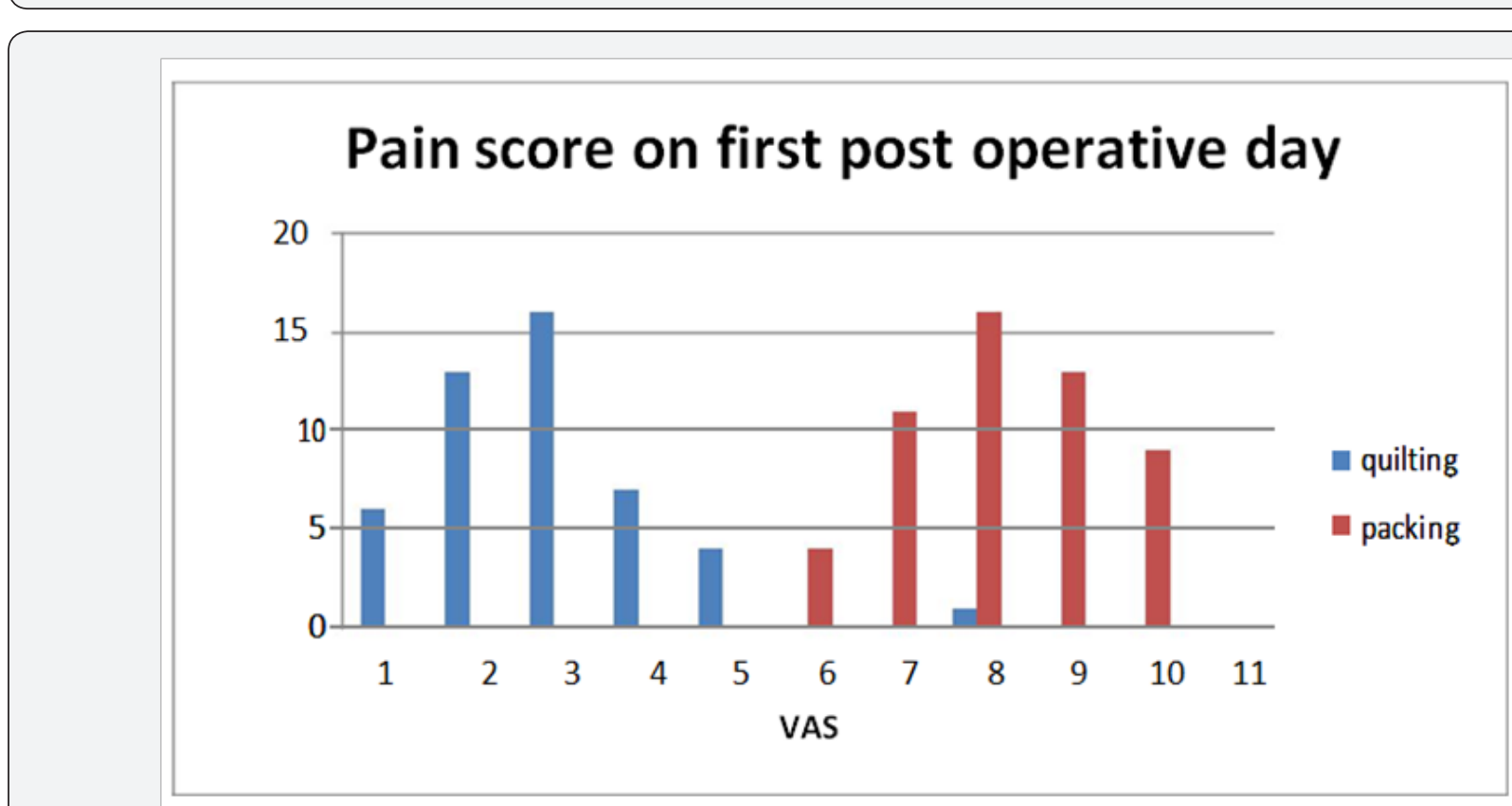

Figure 2: VAS reading on severity of pain on the first post operative day. 


\section{Global Journal of Otolaryngology}

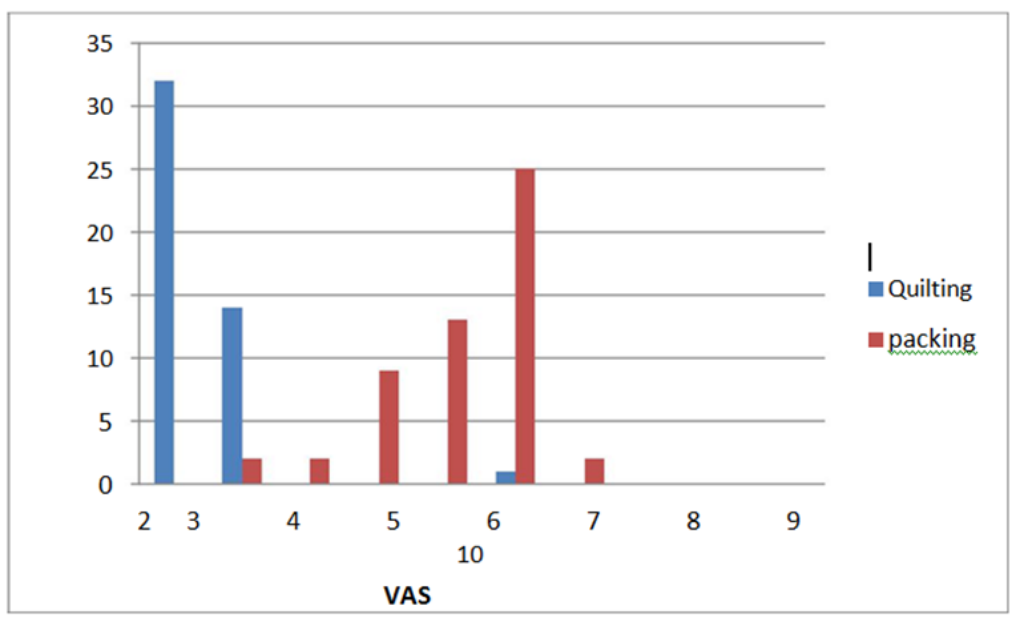

Figure 3: VAS reading on severity of pain on the day of discharge.

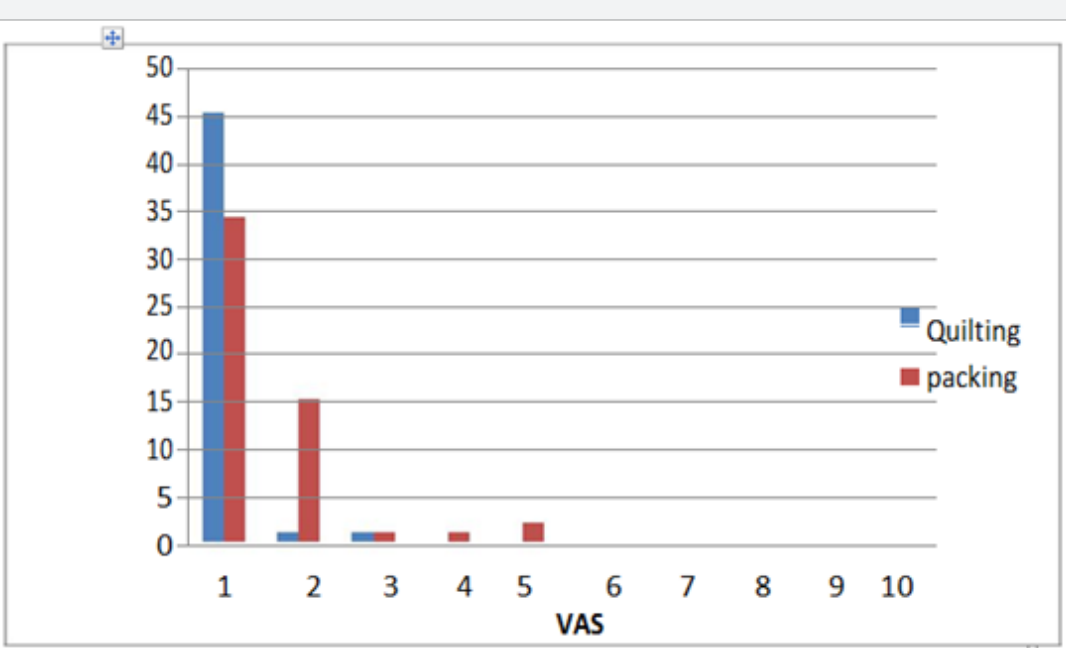

Figure 4: VAS reading on severity of pain on first follow- up.

Table 1: Student $t$ test for VAS on day of operation.

\begin{tabular}{|c|c|c|c|c|}
\hline V2 & N & Mean & Std. Deviation & Std. Error Mean \\
\hline Pain on day 1 & 47 & 3.57 & 1.098 & .160 \\
\hline 2 & 53 & 7.66 & .939 & .129 \\
\hline
\end{tabular}

Table 2: Student $t$ test for VAS on first post operative day, day of discharge and first follow up.

\begin{tabular}{|c|c|c|c|c|c|}
\hline V2 & & $\mathbf{N}$ & Mean & $\begin{array}{c}\text { Std. } \\
\text { Deviation }\end{array}$ & $\begin{array}{c}\text { Std. Error } \\
\text { Mean }\end{array}$ \\
\hline Pain 1 ${ }^{\text {st }}$ POD & 1 & 47 & 1.89 & 1.355 & .198 \\
\hline & 2 & 53 & 7.23 & 1.187 & .163 \\
\hline Painondis charge & 1 & 47 & .40 & .825 & .120 \\
\hline & 2 & 53 & 4.19 & 1.128 & .155 \\
\hline Pain 1 ${ }^{\text {st }}$ followup & 1 & 47 & .06 & .323 & .047 \\
\hline & 2 & 53 & .53 & .932 & .128 \\
\hline
\end{tabular}

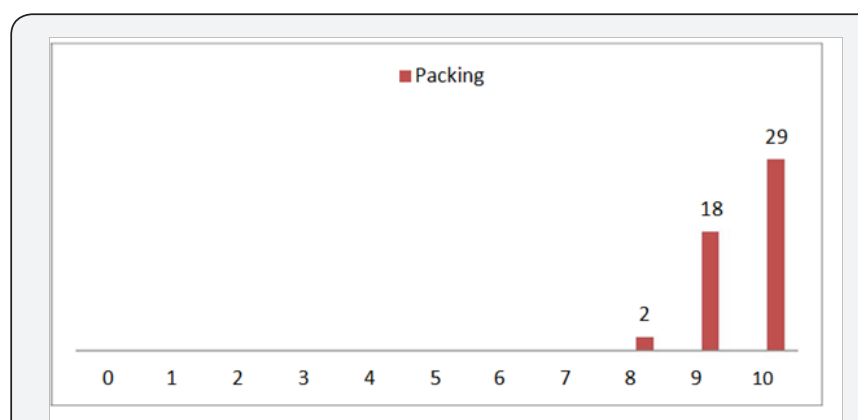

Figure 5: VAS reading on the day of pack removal/no pack in quilting.

\section{Discussion}

Septoplasty is the surgery done for the treatment of symptomatic deviated nasal septum. Deviations of nasal septum are extremely common. Morrell McKenzie studied over 2000 skulls and found only $23 \%$ had a straight septum 
[2]. Nasal obstruction is the feeling of blockage or insufficient air flow through the nose and it can impact significantly on the individual's Quality of Life (QL) [3]. Nasal packing after nasal surgery was started by Gustay Killian of Germany on 1847 [4] and has been practiced as a routine procedure since then. The pain and distress caused by the procedure while introduction and more so in removal raises a question on its absolute need. Septoplasty with quilting of nasal septum is a procedure adopted to improve such condition. Here the knot is placed in the posterior part of the nasal septum after removal of deviated part and is brought anteriorly with continuous suture. This procedure prevents complications such as septal haematoma and bleeding. It is also helpful in closing any inadvertent tears of septal mucosa. The suture when placed through the middle turbinates, helps to stabilize them during the healing process [5].

This study reveals significant level of pain due to packing on all days under study $(\mathrm{p}<0.001)$ and much more on pack removal in all except 2 revealing VAS reading 9 and Similar results were seen on discomfort and pain score in studies done by Shah $S$ et al [6], Rashid A et al [7], Ansari et al [8] with significant rise in mean pain score among patients with nasal pack than quilting. Nasal packing causes acute and complete obstruction of nasal airways. This leads to obligatory oral breathing. Rhinologists are well versed with the local effects but are quite unaware of its systemic effects. Systemic complications induced by nasal packing are poor sleep quality, respiratory difficulty, decreased oxygen saturation and toxic shock syndrome [9]. Nasal packing compromises respiration leading to hypoxemia, daytime somnolence and exaggeration of pulmonary dysfunction especially in elderly patients. When the factors are complicated by acute anemia of blood loss, they can lead to serious tissue hypoxia, which may sometimes prove fatal [10]. The study revealed VAS reading on the day of pack removal of the patients with nasal packing was maximum signifying severe pain in nasal packing group which was seen to be similar in another study done by Mane RS et al. [11] where the author mentioned that pain experienced by the patient at the time of pack removal, although of short duration, is vividly remembered as a very painful experience. Study by Orlandi shows that placement of nasal packs can be avoided after nasal surgeries to lower the risks, cost and discomfort associated with this intervention [12]. In a similar study done by Gunaydin RO revealed that extubation was more comfortable and pain score was significantly less in patients with septal suturing than with nasal packing. Korkut A $Y$ et al. [13] in their research suggested that tras-septal suturing in septoplasty is an easy modification with only a little increase in surgery time [14].

\section{Conclusion}

The pain and discomfort caused by nasal packing can be avoided by quilting of nasal septum. Thus packing of nasal cavity should be avoided where possible and reserved for those who had bleeding predisposition or complication.

\section{Recommendation}

Nasal Septal suturing or quilting is a much safer and a more comfortable procedure to the patient. So it should be practiced more avidly by ENT surgeons.

\section{Limitation of The Study}

Quilting is a procedure which requires practice and expertise thus it may be difficult for novice.

\section{Acknowledgement}

The author would like to acknowledge all the participants and everyone who contributed directly and indirectly to make this study a success.

\section{References}

1. Singh S, Singh J, Kakkar V, Yadav SPS, Bishnoi A, et al. (2015) To Evaluate the Effects of Nasal Packing on Blood Oxygen Saturation. Otorhinolaryngology Clinic: An International Journal 7(2): 41-44.

2. McKenzie M (1880-1884) Manual of diseases of the nose and throat. London: Churchill 2: 432.

3. Bezerra TF, Stewart MG, Fornazieri MA, Pilan RR, Pinna Fde R, et al. (2012) Quality of Life assessment septoplasty in patients with nasal obstruction. Braz J Otorhinolaryngol 78(3): 57-62.

4. Price JC Septoplasy (1990) In: Johns ME; Price CP; Mattox DE, eds: Atlas of head and neck surgery. Philadelphia: BC. Decker 1: 109-120.

5. Hari C, Marnane C, Wormald PJ (2008) Quilting sutures for nasal septum. J Laryngol Otol 122(5): 522-523.

6. Shah S, Kumari S, Pradhan B, Thapa N (2010) Outcomes of Endoscopic Quilting of Nasal Septum Verses Nasal packing Following Septoplasty. The international journal of Otorhinolaryngology. 13(2).

7. Rasid A, Aziz B, Khan MA, Hameed A (2011) Alytical assessment of Nasal Packing in Septoplasty. PJMHS 5(2): 232-235.

8. Ansari MA, Islam U, Hirani I, IAM Khayani, Ziauddin A, et al. (2013) Trans-septal suturing technique without intra-nasal packing in nasal septal surgery. Pak J Surg 29(2): 123-126.

9. Sedwick JD, Lopez AB, Gajerwski BJ, Simons RL (2005) Caudal septoplasty for treatment of septal deviations: aesthetic and functional correction of the nasal base. Arch Facial Plat Surg 7(3): 158-162.

10. Singh S, Singh J, Kakkar V, Yadav SPS, Boshnoi A, et al. (2015) To Evaluate the Effects of Nasal Packing on Blood Oxygen Saturation. Otorhinolaryngology Clinics: An International Journal 7(2): 41-44.

11. Mane RS, Patel B, Mohite A (2013) Comparison of Septoplasty With and Without Nasal Packing and Review of literature. Indian J Otolaryngol Head Neck Surg 65(2): 406-408.

12. Orlandi RR, Lanza DC. Is nasal packing necessary following endoscopic sinus surgery? Laryngoscope 114(9): 1541-1544.

13. Gunaydin RO, Aygene E, Karakullukcu S, Fidan F, Celikkanat S (2011) Nasal packing and tras-septal suturing techniques: surgical and anaesthetic prospective. Eur Arch Otorhinolaryngol 268(8): 11511156.

14. Korkut AY, Teker AM, Eren SB, Gedikli O, Askiner O (2010) A randomized prospective trial of trans-septal suturing using a novel device verses nasal packing for septoplasty. Rhiniology 48(2): 179-182. 

(C) This work is licensed under Creative

DOI: $10.19080 /$ GJO.2018.13.555866

\section{Your next submission with Juniper Publishers} will reach you the below assets

- Quality Editorial service

- Swift Peer Review

- Reprints availability

- E-prints Service

- Manuscript Podcast for convenient understanding

- Global attainment for your research

- Manuscript accessibility in different formats

( Pdf, E-pub, Full Text, Audio)

- Unceasing customer service

Track the below URL for one-step submission https://juniperpublishers.com/online-submission.php 